\title{
O trabalho do ator sobre si mesmo: memória, ação, linguagem e silêncio
}

An actor prepares: memory, action, language and silence

Andrea Copeliovitch ${ }^{1}$

1.

Professora Associada do Departamento de Artes da Universidade Federal RESUMO

Para Stanislavski, a pesquisa em teatro se dá no "si mesmo" do ator. Pesquisar o si mesmo é pesquisar a vida inteira; no caso do teatro, é fazer a vida acontecer na cena. O acontecimento da vida no palco é o acontecimento desse si mesmo com todas as suas complexidades; é tornar-se linguagem própria à cena. O si mesmo, em constante transformação na impermanência do tempo, constitui seu repertório de vivências e revivescências e nos traz questões fundamentais como memória, ação, linguagem e silêncio.

Palavras-chave: Si-mesmo. Linguagem. Memória.

\section{ABSTRACT}

For Stanislauski the research in theatre happens in the actor's self. Searching for one's self means a lifelong research; in theatre, it means making life happen on stage. Life happening on stage is becoming language inherent to the scene. In constant transformation during time impermanence, we are constituted by our repertoire of experiences, reviviscences and fundamental questions such as memory, action, language and silence.

Keywords: Self. Language. Memory.

Permanente do Programa de Pós-Graduação em Estudos Contemporâneos das Artes. Contato: copeliovitch@hotmail.com ORCID: http://orcid.org/ 0000-0002-8169-5005

Submetido em: 28/07/2016, aceito em: 12/11/2016. 
Prólogo

Quando Konstantin Stanislavski assistiu a esse espetáculo ruim, a plateia aplaudiu. Quem disse então que era ruim?

Stanislavski viu os trejeitos dos atores, a voz mal cantada, as entonações monótonas, repetitivas, independentes de sentido; apenas a boa entonação, capaz de ser escutada pelo bom ouvido, habituado àquela música falada sem dizer nada. Quando o ator falou da morte do filho, das inúmeras vitórias ou das infinitas histórias, tudo era a mesma canção, cantada com ombros tensos e a mão direita estendida.

Mas o teatro, essa arte pobre, dos cantores que não cantam tão bem e dos bailarinos que não dançam tão bem, pode bem existir dessa maneira: basta um cenário bonito, um bom figurino, uma iluminação competente, maquiagem e direção e está feito o espetáculo, esse pobre coitado.

Stanislavski percebeu o descaso das marcações, a utilização dos braços erguidos como ênfase nas cenas, os gestos inúteis, trejeitos, sujeitos, mal feitos. Percursos e discursos que não levam a lugar nenhum, sem partida e sem chegada. Ações sem intenções, sem tensões, sem oposições, sem atenção.

Afinal qualquer coisa pode ser teatro - basta o bom cenário, figurino etc. Mas o que é, afinal, o tal teatro? E Jerzy Grotowski disse o que não é, disse que aquele espetáculo a que Konstantin assistiu e de que não gostou não era teatro.

Para explicar porque aquilo não era teatro, Grotowski, artesão que era, foi à sua artesania ver de que ela prescindia. Não era preciso, disse ele, o cenário bonito, nem o bom figurino, nem a iluminação competente, nem mesmo a maquiagem. Mas então o que sobra dessa tal arte?

Um ator e um espectador, e algo acontece entre eles. Acontecimento mágico, alquímico, transformador. Artaud, trancado no hospício, falou que o teatro precisava ter o impacto da peste sobre as pessoas.

Uma pessoa atravessou um espaço vazio e alguém parou para observar. Parou porque era imprescindível observar, havia algo naquele caminhar: sentido, tensão, intenção, atenção, dentro de um foco, de um tempo/ritmo que lançou aquele que observava dentro de espaço- tempo vazio de cotidiano e preenchido pela magia de mundo instaurado, criado por um ator/autor/atleta afetivo, capaz de emitir jatos de energia para partes do corpo do observador encantado, transportado por essa arte tornada veículo.

Referências, notas e reflexões sobre o prólogo

Toporkov nos conta sobre um de seus primeiros encontros com Stanislavski: 
Comecei a elogiar uma produção de grande sucesso em Moscou (eu sabia que Stanislavski havia visto), de repente vi tal horror em seus olhos que eu tive de parar no meio da frase. Só depois de muitos anos fui perceber quão inepto eu havia sido. Stanislavski investiu contra o teatro e seu diretor, primeiro com raiva, em seguida, sarcasticamente, revelando a inadequação do pensamento que está por trás da produção e, em seguida, de forma inesperada, característica a sua natureza, em um único gesto altamente expressivo ${ }^{2}$ (TOPORKOV, 2004, p. 13, tradução livre).

Que detalhe aparentemente sutil desagradou o mestre nesse espetáculo e passou despercebido para Toporkov? Esse mesmo detalhe de interpretação parece seguir desagradando aqueles que se aprofundam no estudo desses grandes mestres como Stanislavski, Meyerhold, Grotowski, Peter Brook, mas segue agradando a uma boa parte do grande público. Qual a validade dessa crítica? Deixemos que o próprio mestre Stanislavski responda a essa questão:

Nós estávamos protestando contra a forma de se atuar no palco, contra a teatralidade e o pathos afetado, a declamação e a representação exageradas, contra o sistema de estrelato que arruinava o ensemble, contra o modo como as peças eram escritas, contra a insignificância dos repertórios. A fim de rejuvenescer a arte, declaramos guerra contra todos os convencionalismos do teatro: no desempenho, direção, cenários, trajes, entendimento das peças etc. (STANISLAVSIKI, apud GUINSBURG, 1985, p. 40).

Comecemos pela voz do ator. Podemos pensar na primeira frase dita em espetáculo circense: - "Respeitável público, senhoras e senhores: o Grande Circo Tal tem o prazer de apresentar o maior espetáculo da terra!”

Essa apresentação possui uma melodia bem conhecida pelo público. Quantas frases em espetáculos são ditas seguindo essa linha melódica? Escutamos essa melodia adaptada e entoada: "Ser ou não ser, eis a questão"3 (SHAKESPEARE, 1997, p. 1087).

Ou, se apurarmos o ouvido, podemos identificar ainda linhas melódicas de brincadeiras infantis como "batatinha quando nasce". O problema acontece quando isso se dá sem uma intencionalidade, quando não há consciência dos caminhos dessa voz. Essa voz de ator não buscou seguir uma tradição como no circo ou na brincadeira infantil: apenas encontrou um lugar comum melódico e o repetiu.

Pode o teatro sustentar a sua vida sem cair nas "artimanhas do tédio" (BROOK, 1999) apenas com essa imitação sem intenção nem tradição? E estamos falando apenas da voz! Nem falamos sobre a mão direita que se ergue enfaticamente, nem
2.

"I started to pray a highly successful production in Moscow (I knew Stanislavski had seen it), I suddenly saw such horror in his eyes that I had to stop mid-sentence. Only after many years did I realize how inept I had been. Stanislavski inveighed against that theatre and its director, first angrily then sarcastically, revealing the inadequacy of the thinking that lay behind the production, and then, unexpectedly, characterized its nature in one single highly expressive gesture".

3.

"To be or not to be"

(SHAKESPEARE, 1997 -

Hamlet. Ato 3, cena I, linha 57, p. 1087). 
dos ombros tensionados, nem dos pés que parecem não ter forças para sustentar o corpo.

Quando eu era uma jovem atriz, nos anos 1990, o grande ícone dos palcos paulistanos era a Bete Coelho. Eu imitava as linhas melódicas de Bete Coelho em "Electra Com Creta", espetáculo dirigido por Gerald Thomas em 1987.

Até hoje consigo reconhecer essa forma de falar em jovens atores considerados muito bons. Mas até que ponto essa forma de falar é uma coincidência de uma organicidade semelhante entre esses atores e a maravilhosa Bete Coelho, ou é apenas uma imitação sem sequer a consciência desse referencial externo?

Stanislavski percebeu que muitos atores menos conhecidos de sua época imitavam os grandes atores. Jacob Guinsburg enfatiza a didática da época, que se dava nos conservatórios surgidos na segunda metade do século XIX, onde grandes atores ensinavam através da imitação (GUINSBURG, 1985). Então temos esses espetáculos em que os atores possuem boa dicção e a tensão concentrada na mão direita, que erguem enfaticamente diante do público. Tudo isso Stanislavski percebeu ao longo de sua vida. Como relaxar esses músculos da mão e do ombro? É preciso entender de onde vêm essas tensões, o que nos impulsiona, o que nos torna complexos. Stanislavski dedicou sua vida a entender o trabalho ator, que ele chamou de trabalho sobre si mesmo, como são originalmente intitulados dois de seus livros": Rabota Aktera nad Soboj - $v$ tvortsheskom protsesse perezhivanie. Tshast I (1938) e Rabota Aktera nad Soboj $v$ tvortsheskom protsesse voploshshenija. Tshast II (1948) ${ }^{5}$.

Stanislavski pesquisa o si mesmo. Pesquisar o si mesmo é pesquisar a vida inteira; o mestre queria fazer a vida acontecer no palco. Que vida é essa que acontece no palco? O acontecimento da vida no palco não está relacionado com a estética do realismo-naturalismo, como um olhar superficial pode entender. A vida no palco é o acontecimento desse si mesmo com todas as suas complexidades. É tornar-se linguagem própria ao palco. E que linguagem é essa? A linguagem do teatro não é o texto dramático, como já havia percebido Antonin Artaud, ator, diretor e pensador teatral do século XX que viveu boa parte de sua vida trancafiado em manicômios:

Considerando-se essa sujeição do teatro à palavra, é possível perguntar se o teatro por acaso não possuiria sua linguagem própria, se seria absolutamente quimérico considerá-lo como uma arte independente e autônoma, assim como a música, a pintura, a dança, etc. (ARTAUD, 1999, p. 76).

Não é sempre que um espetáculo alcança essa linguagem: muitas vezes caímos na superficialidade da recitação do texto,
4.

Claro que se a imitação é proposital, o resultado será diferente, mas não vamos entrar nesse mérito.

5.

Na tradução em espanhol, o volune I é El Trabajo del Actor Sobre Sí Mismo en el Proceso Creador de las Vivencias. Tradução de Salomón Merener. Buenos Aires: Quetzal. 1980 e o volume II é El Trabajo del Actor Sobre Sí Mismo en el Proceso Creador de la Encarnación. Tradução de Salomón Merener. Buenos Aires: Quetzal. 1983. 
da imitação, mas encobrimos essas superficialidades com um bom cenário, um bom figurino etc. Para Artaud, essa linguagem ia além da organicidade proposta por Stanislavski: para ele era necessário que o teatro fosse tão potente em seu poder de transformação como a peste. O catalisador dessa transformação é o ator, com perfeito domínio de si mesmo. Esse domínio, ainda seguindo o pensamento de Artaud em "Um Atletismo Afetivo" (ARTAUD, 1999), resulta no controle da emissão de energia. Para obter esse controle, o ator treina seu si mesmo ${ }^{6}$ : corpo/ voz/energia/afetividade; dessa maneira é capaz de irradiar essa energia, conhece o movimento da energia em seu corpo, aprende a direcioná-la.

É preciso admitir, no ator, uma espécie de musculatura afetiva que corresponde a localizações físicas dos sentimentos. [...]

$\mathrm{O}$ ator dotado encontra em seu instinto o modo de captar e irradiar certas forças; mas essas forças, que têm seu trajeto material de órgãos e nos órgãos, ele se espantaria se lhe fosse revelado que elas existem, pois nunca pensou que pudessem existir (ARTAUD, 1999, p. 162).

Anos mais tarde, Jerzy Grotowski consegue realizar esse sonho artaudiano de um atleta afetivo pesquisando, treinando com seus atores durante extensas horas diárias, inicialmente em uma cidadezinha da Polônia chamada Opole. Ele parte dos ensinamentos de Stanislavski para realizar sua pesquisa em teatro. Ele observa o acontecimento teatral. O que é superficial nesse acontecimento? Grotowski percebe que para acontecer teatro, elementos tais como figurino, palco, iluminação são desnecessários: "Podemos então definir o teatro como o que ocorre entre o espectador e o ator. Todas as outras coisas são suplementares" (GROTOWSIKI, 1971, p. 18).

Mas o que acontece entre ator e espectador? É sobre a potência desse acontecimento tão raro que Artaud refletiu, usando termos como o mágico, o transformador e o alquímico (ARTAUD, 1999).

Teatro, memória e linguagem

Stanislavski constatou que o trabalho do ator ia muito além da recitação do texto e que era necessário que ele se preparasse (STANISLAVSKI, 1980). O que é essa preparação? Por onde começar? Um pintor começa a partir de uma tela em branco... O que é a tela em branco do ator?

$\mathrm{O}$ ator e diretor peruano Alberto Ísola fala que os textos de Tchekov inserem o não dito na linguagem teatral, a pausa (ÍSOLA, 2014).
6.

Stanislavski já havia compreendido que era imprescindível a preparação do ator, não apenas o ensaio, mas o treinamento. 
O drama de Tchekov é feito de silêncio, de reticências, de não dizer o que se pensa, de não dizer à parte: nem diz o narrador, nem o coro. Apenas o silêncio. Stanislavski começa a preparação do ator, seu trabalho sobre si mesmo a partir do acontecimento desse silêncio encontrado no texto. Nesse silêncio é preciso acontecer vida. É uma vida que o ator cria. Nesse momento em que falamos de Stanislavski e Tchekov, descobrimos a vida interior de um papel, subtexto, memória afetiva, objetivos, foco. É no silêncio que inicia a preparação do ator que surgem os primeiros elementos do chamado "método Stanislavski"7. A vida interior precisa acontecer no silêncio da pausa, o não dito precisa dizer algo, o invisível tornar-se visível, ou cognoscível. Para realizar todos esses acontecimentos, que vão muito além da recitação do texto, o ator se prepara, o ator cria, o ator age.

Qual é a matéria-prima de seu trabalho? Ele mesmo, não é o corpo nem a mente separados, nem o texto, nem o palco; mas ele mesmo, com todo o seu repertório.

O que é o repertório de um ator? O que é o repertório de uma pessoa? São as experiências, vivências, aquilo que foi aprendido e o que foi esquecido também; o consciente e o inconsciente, a herança genética, cultural...

Como se acessa esse repertório? Stanislavski passou a vida pesquisando as possibilidades de acesso a esse repertório. Como reviver ou revivescer o que o ator traz dentro do si mesmo? O mestre subtitula o tomo I de "O trabalho do ator sobre si mesmo" no processo criador de Perezhivanie (ZALTRON, 2014). Segundo Ruffini:

\footnotetext{
Perezhivanie (que poderia ser traduzida como "revivescer" num sentido quase biológico, como quando uma semente congelada "revivesce") não é nem a finalidade do sistema, nem seu único (e privilegiado) aspecto, É somente a parte psicomental de um trabalho mais compreensivo cujo aspecto físico é a personificação. Perezhivanie ativa a sensibilidade cênica interna e a personificação ativa a sensibilidade cênica externa. Mas o ator deve adquirir uma sensibilidade cênica geral: a síntese. não a soma. das duas sensibilidades cênicas, interna e externa. [...]

A mente do ator stanislavskiano em perezhivanie é realmente uma mente dilatada. (RUFFINI, apud BARBA, SAVARESE, 1995, p. 65).
}

Stanislavski percebeu que o resgate da memória resulta na emoção (memória emotiva), porém que essa emoção, apesar de toda a poesia e beleza de tigre selvagem, é indomável. O que temos de matéria-prima concreta para resgatar é a ação. Stanislavski dizia:
7 .

Observemos que esse método é vivo e que se transformou ao longo da vida de Stanislavski, e que continua se transformando em sua função primordial que é de dar vida ao ator em cena. 
Se a sequência de ações físicas seguir suas próprias circunstâncias pessoais na vida, se tiver o seu cunho pessoal, então não é preciso se preocupar se seus sentimentos secarem. Volte para as ações físicas e elas vão restaurar seus sentimentos. (STANISLAVSKI, apud TOPORKOV, 2004, p. 124) 8 .

A ação a ser resgatada vem de memórias antigas e construídas no processo de treinamento, no estudo do texto e no estudo do silêncio. Essa ação se dá no corpo do ator. Ação física é a unidade de trabalho do ator em seu instrumento, o si mesmo. Essa ação, como palavras em um poema, notas em uma música, torna-se linguagem nem cena, linguagem própria à cena, que não busca representar a realidade cotidiana, mas cria uma realidade no aqui e agora do acontecimento do teatro.

Teatro e espaço vazio

Posso escolher qualquer espaço vazio e considerá-lo um palco nu. Um homem atravessa este espaço vazio enquanto outro o observa, e isso é suficiente para criar uma ação cênica

(BROOK, 1970, p. 4).

Vir a ser ator consiste em atravessar o palco vazio e levar consigo o observador. Mesmo que este não saia do seu ponto no espaço, de sua imobilidade física de observador, também ele atravessou o espaço vazio. É a superação dessa dificuldade de transportar o outro consigo ao realizar a sua ação que faz da cena uma cena no espaço vazio.

O que é, afinal, este espaço vazio? O espaço é tridimensional; é nele que habitam as coisas, é onde ocorrem os fenômenos, como ele pode estar vazio? Estar vazio parece ser circunstancial, é um momento na existência do espaço no aguardo do ator que vai atravessá-lo. O espaço vazio que antecede o acontecimento da caminhada é o silêncio antes do som, é a tela em branco antes do quadro. É o princípio. O princípio é criado. No meio do burburinho do cotidiano, nós atores silenciamos a linguagem conhecida de nosso si mesmo e esvaziamos o espaço para que uma nova realidade se instaure. Segundo Brook:

Para que alguma coisa relevante ocorra, é preciso criar um espaço vazio. $O$ espaço vazio permite que surja um fenômeno novo, porque tudo que diz respeito ao conteúdo, significado, expressão, linguagem e música só pode existir se a experiência for nova e original. Mas nenhuma experiência nova e original é possível se não houver um espaço puro, virgem, pronto para recebê-la (BROOK, 2011, p. J).

O estado de vazio não é o cotidiano. Por ser um momento que antecede todo o movimento é preciso atentar a ele,
8. Observemos que esse método é vivo e que se transformou ao longo da vida de Stanislavski, e que continua se transformando em sua função primordial que é de dar vida ao ator em cena. 
é preciso alterar a velocidade do tempo do cotidiano para configurar o vazio, e assim, atravessá-lo e chamar a atenção do observador.

A mágica do ator começa antes da travessia - depois chamaremos esta mágica de poiesis. Ela começa na instauração do espaço vazio, ou melhor, na decisão de instaurar o espaço vazio.

O agir do ator é mágico, no sentido de que é não cotidiano e transformador. É alquímico. O alquimista é o que transforma um metal qualquer em ouro. Já dizia Artaud que "Entre o princípio do teatro e o da alquimia há uma misteriosa identidade de essência" (ARTAUD,1999, p. 49).

$\mathrm{O}$ ator, a partir do seu agir, é transformador do tempo e do espaço, tanto no sentido mais óbvio, ou seja: do ator que conta uma estória como um personagem e uma vida inteira passa diante do espectador no tempo cronológico de duas horas; como neste sentido primário e primordial do espaço vazio.

\begin{abstract}
Vamos ao teatro para um encontro com a vida, mas se não houver diferença entre a vida lá fora e a vida em cena, o teatro não terá sentido. Não há razão para fazê-lo. Se aceitarmos, porém, que a vida no teatro é mais visível, mais vívida do que lá fora, então veremos que é a mesma coisa e, ao mesmo tempo, um tanto diferente. Convém acrescentar algumas particularidades. A vida no teatro é mais compreensível e intensa porque é mais concentrada. A limitação do espaço e a compressão do tempo criam essa concentração (BROOK, 2011, p. 8).
\end{abstract}

O metal menos nobre e o ouro são metais, mas não são o mesmo em sua semelhança metálica. O ouro da arte do ator é obtido através desse processo alquímico que esvazia o espaço e transforma o seu agir em catalisador de sonhos, que conduz o espectador ao silêncio e ao vazio, e depois, à travessia.

$\mathrm{O}$ agir do ator é poético, atenta para a realidade e traz à tona a linguagem além do cotidiano, nos torna observadores do espaço vazio. O espaço de mundo instaurado pelo teatro. Esse teatro não tem elementos supérfluos: muda a velocidade do tédio e da inércia cotidiana, muda o tempo. Esse teatro alquímico, orgânico, pobre, apresenta o tempo do essencial, o espaço se esvazia e dele brota a poiesis. Segundo Manuel Antônio de Castro:

A poiesis não é qualquer agir, por exemplo, o do nosso corpo que cresce. Mas a percepção de corpo e do crescimento já se dá porque a poiesis ocorre como logos, ou seja, Linguagem. Linguagem não é língua, mas a manifestação do real enquanto sentido e verdade (CASTRO, 2014, p.3).

O movimento do ator atravessando o espaço é poiesis. Esse movimento pode ser somente uma respiração, a pulsação na 
imobilidade do gesto, ou uma corrida tresloucada, uma dança feita de oposições e desequilíbrios.

Muitas vezes o ator está cruzando espaços, mas não está em ação: atravessa espaços que não estão vazios, não há poiesis em seu movimento, não há vazio em seu espaço, apenas seu gesto é vazio. Shakespeare já havia percebido isso no século XVI:

\begin{abstract}
HAMLET: Peço uma coisa, falem essas falas como eu as pronunciei, língua ágil, bem claro; se é pra berrar as palavras, como fazem tantos de nossos atores, eu chamo o pregoeiro público pra dizer minhas frases. E nem serrem o ar com a mão, o tempo todo (Faz gestos no ar com as mãos.); moderação em tudo; pois mesmo na torrente, tempestade, eu diria até no torvelinho da paixão, é preciso conceber e exprimir sobriedade - o que engrandece a ação. Ah, me dói na alma ouvir um desses latagões robustos, de peruca enorme, estraçalhando uma paixão até fazê-la em trapos, arrebentando os tímpanos dos basbaques que, de modo geral, só apreciam berros e pantomimas sem qualquer sentido. A vontade é mandar açoitar esse indivíduo, mais tirânico do que Termagante, mais heroico do que Herodes. Evitem isso, por favor. (SHAKESPEARE, 2016, p. 55).
\end{abstract}

Esvaziar o espaço é tirar toda a significação e todos os ruídos anteriores àquele momento para utilizar esse espaço como origem de algo novo - novo no sentido de que é nascido e revivescido naquele instante, no momento presente, na cena: presença.

\title{
Memória e ação física
}

O ser humano tem essa capacidade da memória. Uma memória que vai além de lembranças involuntárias ou traumas. Há memórias que podem ser ativadas de acordo com nossa vontade. Memória, Musa e Mímesis têm o mesmo radical grego mni' (JARDIM, 1994). Essas três palavras associadas - poiesis, ação física e imaginação - compõem a arte do ator, seu repertório. Memória diz respeito a quem somos existencialmente. A criação do ator é imbuída de seu repertório, do vocabulário que ele construiu ou aprendeu ao longo dos anos. Esse vocabulário se constitui da memória da pele, da memória das histórias, das tradições do ofício aprendidas, praticadas, ressignificadas, memória da vida imitada - mímesis. A inspiração vem das musas; Musa é a inspiração e as Musas são filhas de Mnemosine/ Memória. Memória é a capacidade de lembrar, é o que nos faz ser no tempo, que nos torna históricos. Temos passado, temos memórias ainda não vividas no devir, memórias imaginadas em tempos imemoriáveis e somos no presente. 
Mímesis é a capacidade de repetir o lembrado. Poiesis é a ação que se manifesta: o movimento que parte da escuta e da memória. A imagem se torna ação. A poiesis do ator se repete, é mimética, não no sentido de ser uma imitação simulacro do real (PLATÃO, 2004), mas na capacidade de imitar a si mesma. A arte do ator é a arte da repetição, da capacidade de repetir como se fosse pela primeira vez.

No teatro não é necessária a mesma vida com sua verdade mas a condicionalidade cênica bela capaz de idealizar a vidas (STANISLAVSKI, 1980, p. 199).

A vida que se cria na cena é verdade e é vida, mas como o metal comum e o ouro, não é a mesma verdade da vida cotidiana: é polida, é transformada pela arte do ator/poeta.

O poeta é aquele capaz de escutar as musas. Só se escutam as musas no silêncio, quando se consegue calar todo o resto. $O$ poeta é capaz de tornar a voz da musa audível para o mundo. Dessa forma, a poiesis do ator, seu agir, é tornar esse repertório composto de memória e imaginação: visível, audível e sensível, concreto no próprio corpo, concreto no "si mesmo", como o mestre Stanislavski designava a arte do ator: si mesmo é composto pelo corpo e suas vivências, vivências acontecidas e imaginadas, a ser revivescidas através de ações poéticas, ou ações físicas, como denominou Stanislavski. Segundo Toporkov, o método das ações físicas era o segredo de Stanislavski:

Naquela época, eu ainda não compreendera o significado completo desse tipo de trabalho, eu não sabia o significado de segredo de Stanislavski. Que, ao realizar ações físicas sinceramente e seguir sua lógica e sequência, é possível alcançar os sentimentos mais complexos e experiênciasg (TOPORIKOV, 2004, p.175).

Toporkov, no relato de sua experiência com Stanislavski, conta ainda que o mestre dizia que concentrar na ação física era uma forma de tirar o foco do trabalho do ator da emoção. A emoção é da ordem do intangível.

Ação física é a forma de o ator trazer para o espaço palpável e visível do corpo essas revivescências, buscando o essencial de cada uma delas. São memórias revividas e polidas. São inscritas no corpo do si mesmo do ator a partir da poiesis. Ação física não é simulacro.

Linguagem e pesquisa

Poiesis é o agir, mas um agir a partir da linguagem. O que quer dizer isso? Agir e linguagem? Quando a gente se aprofunda no 
pensamento, vemos que as palavras são questões. Toda palavra vem com a questão embutida: o que é? O que é palavra? O que é ator? O que é teatro? A palavra em si não é a resposta, mas um espaço mínimo de compreensão traduzido e que pode ser usado para a comunicação, ou um espaço de linguagem, que na poesia não busca traduzir, mas traz à tona o seu senso de questão, da relação do homem com o mundo e sua incapacidade de compreender a totalidade do mesmo. Se linguagem é questão, eu, como sou atriz, sou aquela que age. Agir é minha questão. Que agir é esse? É poiesis, é questão e é linguagem, linguagem posta em cena. Meu agir se dá em cena, se dá no meu corpo. Linguagem está nas minhas vísceras: "A linguagem é a casa do ser, nesta habitação do ser mora o homem. Os pensadores e poetas são os guardas desta habitação (HEIDEGGER, 1973, p. 347). Linguagem é a "casa do ser". É nela que eu habito. A compreensão dessa linguagem e desse agir é a compreensão do meu ser no mundo.

Peter Brook sempre entendeu o teatro como espaço vazio que passa a ser linguagem em ação, poiesis. Ação que não se limita à expressão ou à comunicação. É a linguagem como a casa do ser, destituída da compreensão metafísica de significante e de significado, desassociada da língua, da fala e da expressão simbólica. É uma linguagem-manifesto do ser, revelação do ser, jamais por inteiro, sempre salvaguardando seu mistério. Ao mesmo tempo em que ela expõe este ser no tempo e no espaço, ela o abriga no seu interior, acolhe, recolhe e esconde: casa.

A pesquisa do ator exige um rigor porque, para ter sentido, ela necessita compor um repertório memorável, é o vocabulário da sua linguagem. $O$ ator precisa ter conhecimento de seus mecanismos, ser capaz de buscar na memória e memorizar: repetir. O que é possível repetir? A emoção não é possível repetir. A ação é possível repetir. Uma ação, para Stanislavski, tem um objetivo, um foco (atenção), acontece no tempo e no espaço (vazio), tem ritmo e direção (atravessar).

Ação não deve jamais ser confundida com movimento. Luiz Otávio Burnier dizia que uma ação parte da coluna (BURNIER, 2001). Uma ação possui energia, intensidade, foco, um ponto de partida preciso.

Para Grotowski, no final de sua vida, uma ação podia partir do estado energético suscitado no corpo do ator pelos cantos vibratórios pesquisados por ele (RICHARDS, 1993). Uma ação pode ser dividida em microações, ampliada, dirigida, redirecionada. Uma ação envolve energia, energia para executar e energia que resulta de sua execução. O movimento das partículas no núcleo do elétron é caótico como essa ação, que é fruto do agir humano. Se tentamos despojá-la da instabilidade da 
emoção, ainda assim precisamos estudá-la dentro da complexidade da poiesis, daquilo que se mostra e se oculta, daquilo que é dito, mas que não pode ser explicado. Podemos pensar que a ação física se dá no âmbito da Physys, ela é ação e ela é vida; a repetição é possível e é impossível, pois na vida nada se repete: o ator luta contra a própria vida para criar vida, busca a repetição, busca repetir todas as circunstâncias dadas (STANISLAVSKI, 1970) para que essa ação tenha acontecido pela primeira vez. Ele busca repetir sempre a primeira vez. A primeira vez começa a acontecer sempre no vazio e no silêncio. $O$ ator trabalha a presença, o estar inteiro aqui e agora e as energias se transformam nele e partir dele. Ele busca compreender/realizar essa superação do eu cotidiano que se dá no silenciar dos pensamentos incessantes para abrir-se à escuta das musas, à segunda natureza que foi criada no si mesmo a partir da preparação e treino aos quais se submeteu.

$O$ ator em cena é senhor do tempo, o tempo do ator sai do cronológico e passa a ser outro, tempo sagrado, tempo mágico, tempo sem medida. Medida é a prisão do cotidiano. $\mathrm{O}$ ator cria mundos além do cotidiano, cria tempo e espaço, põe em questão a medida.

Foi na medida que aprendemos as coisas do cotidiano, dividimos: tempo, que vira coleção de horas; linguagem, que vira gramática, sujeito, verbo, objeto, complementos. Ser e agir passam a ser somente a ligação entre o sujeito e o objeto, entre eu e o que está separado de mim, eu sou eu e você é você, e as coisas são coisas, a partir daí eu sou o centro do mundo, que é um conjunto de objetos que eu conceituo e sobre os quais posso emitir juízos de valor. Eu, como sujeito, sou mais importante do que você, objeto.

O acontecimento do teatro propõe um olhar sobre a linguagem, um olhar sem medida e sem juízo, sem preconceito. $O$ caminho do ator se faz de um abrir-se à escuta para seguir o percurso das questões, e trazê-las para o âmbito da Physys, torná-las ações físicas. Essa pesquisa se dá na vida inteira, todos os dias, no si mesmo que sai do próprio umbigo e adentra esse mundo desconhecido de linguagem, questões, mistério e silêncio. 
ARTAUD, Antonin. O Teatro e seu Duplo. 2. ed., São Paulo: Martins Fontes, 1999.

BARBA, Eugenio; SAVARESE, Nicola. A arte secreta do ator: dicionário de antropologia teatral. São Paulo: Hucitec; Campinas, SP: Editora da UNICAMP, 1995.

BROOK, Peter. A Porta Aberta. Rio de Janeiro: Civilização Brasileira, 1999.

BROOK, Peter. Avec Grotowski. Brasília: Teatro Caleidoscópio \& Editora Dulcina, 2011.

BROOK, Peter. O teatro e seu espaço. Petrópolis: Vozes, 1970.

BURNIER, Luís Otávio. A arte de ator: da técnica à representação. Campinas, SP: Editora da Unicamp, 2001.

CASTRO, Manuel Antônio de. Interpretação e ética: afirmação das diferenças culturais como vigor da poiesis. Disponível em: http://www.travessiapoetica.letras.ufrj.br/filosoficos/interpretacaoetica.htm. Acesso em 10 de outubro de 2014.

GROTOWSKI, Jerzy. Em busca de um teatro pobre. Rio de Janeiro: Civilização Brasileira, 1971.

GROTOWSKI, Jerzy. Sobre o Método das Ações Físicas. Palestra proferida por Grotowski no Festival de Teatro de Santo Arcangelo (Itália), emjunhode1988.Disponívelem:http://www.grupotempo. com.br/tex_grot.html, acessado em 20 de outubro de 2014.

GUINSBURG, Jacó. Stanislavski e o Teatro de Arte de Moscou. São Paulo: Perspectiva, 1985.

HEIDEGGER, Martin. Sobre o Humanismo: carta a Jean Beaufret, Paris. São Paulo: Abril Cultural, 1973. (Os Pensadores).

ISOLA, Alberto. Stanislavsky y la idea de la acción. Disponível em: https://www.youtube.com/watch?v=yPSOXr_qU_I Acesso em 20 de outubro de 2014.

JARDIM, Antônio. Música: vigência do pensar poético. Tese de Doutorado. Rio de Janeiro: UFRJ, 1994.

PLATÃO. A República. São Paulo: Nova Cultural, 2004.

RICHARDS, Thomas. Al lavoro con Grotowski sulle azioni fisiche. Milano: Ubulivri, 1993.

SHAKESPEARE, William. The complete works of Shakespeare. Nova York: Longman, 1997.

SHAKESPEARE, William. Hamlet. Disponível em: http://www. encontrosdedramaturgia.com.br/wp-content/uploads/2010/10/ Shakespeare-HAMLET-Tradu\%C3\%A7\%C3\%A30-Mill\%C3\%B4rFernandes.pdf Acesso em: junho de 2016.

STANISLAVSKI, Konstantin. A construção da personagem. 
Tradução de Pontes de Paula Lima. Rio de Janeiro: Civilização Brasileira, 1970.

STANISLAVSIKI, Konstantin. El Trabajo del Actor Sobre Sí Mismo en el Proceso Creador de la Encarnación. Tradução de Salomón Merener. Buenos Aires: Quetzal. 1983.

STANISLAVSKI, Konstantin. El Trabajo del Actor Sobre Sí Mismo en el Proceso Creador de las Vivencias. Tradução de Salomón Merener. Buenos Aires: Quetzal. 1980.

STANISLAVSKI, Konstantin. El trabajo del actor sobre su papel. Tradução de Salomón Merener. Buenos Aires: Editorial Quetzal, 1977.

STANISLAVSKI, Konstantin. Etica y disciplina/Metodo de acciones fisicas (Propedéutica del actor). Seleção e notas de Edgar Ceballos. México: Grupo editorial Gaceta, 1994.

STANISLAVSKI, Konstantin. Mi Vida en el Arte. Habana: Editorial Arte e Literatura, 1980.

STANISLAVSKI, Konstantin. Minha Vida na Arte. Rio de Janeiro: Civilização Brasileira, 1989.

TOPORKOV, Vasily Osipovich. Stanislavski in Rehearsal. Abingdon: Routledge, 2004.

ZALTRON, Michele Almeida. O "trabalho do ator sobre si mesmo" de K. Stanislávski e a "via negativa" de J. Grotowski: confluências ou divergências. In Cadernos Virtuais de Pesquisa em artes cênicas. Vol. 1, n. 1, 2012. Disponível em: http://www. seer.unirio.br/index.php/pesqcenicas/article/view/3024 Acesso em 20 de outubro de 2014. 